\title{
A STUDY OF DYSFUNCTIONAL UTERINE BLEEDING- CLINICAL FACTORS AND ENDOMETRIAL HISTOLOGY
}

\author{
Seena K. B ${ }^{1}$, Ajithkumar V. R2
}

${ }^{1}$ Assistant Professor, Department of Obstetrics and Gynaecology, Government Medical College, Thrissur. ${ }^{2}$ Assistant Professor, Department of Radiotherapy, Government Medical College, Thrissur.

\section{ABSTRACT}

\section{BACKGROUND}

Present study reports the (A) Clinical factors associated with DUB including - 1) Incidence in different age groups, 2) Influence of parity in DUB, 3) Pattern of bleeding seen in DUB, 4) Influence of tubectomy, recent delivery and IUCD insertion on the incidence of DUB and 5) Association of DUB with medical diseases like diabetes and hypertension and (B) Identify the histopathology of endometrial curettage in cases of DUB.

\section{MATERIALS AND METHODS}

The study is of prospective (Observational) type. All patients of adolescent age group, reproductive and perimenopausal age group with history suggestive of dysfunctional uterine bleeding registered as inpatient and outpatient during the period August 1,2010 to July 31, 2011 were studied. A total of 143 cases were selected. DUB forms about $10 \%$ of admissions in Government Medical College Hospital, Thrissur. Out of 156 cases, 143 cases were finally taken for the study.

\section{RESULTS}

The commonest endometrial abnormality was proliferative endometrium. Anovulatory bleeding constituted $70 \%$ and ovulatory bleeding $30 \%$.

\section{CONCLUSION}

Uterine curettage is an important tool as depending on the functional status of the endometrium treatment can be planned.

\section{KEYWORDS}

Abnormal Uterine Bleeding; Dysfunctional Uterine Bleeding; Ovulatory; Anovulatory; Endometrial Histology.

HOW TO CITE THIS ARTICLE: Seena KB, Ajithkumar VR. A study of dysfunctional uterine bleeding - clinical factors and endometrial histology. J. Evolution Med. Dent. Sci. 2017;6(19):1494-1497, DOI: 10.14260/Jemds/2017/327

\section{BACKGROUND}

Abnormal uterine bleeding affects $10-30$ percent of reproductive aged women and up to 50 percent of perimenopausal women. Factors that impact the incidence most greatly are age and reproductive status. ${ }^{1}$

Abnormal uterine bleeding can be due to the following-

1. Organic Causes -

a. Diseases of the genital tract.

b. Systemic diseases.

2. Dysfunctional uterine bleeding -

a. Diseases of the Genital tract -

i. Pregnancy-related conditions.

ii. IUCD - related bleeding.

iii. Benign conditions - Endometriosis, Adenomyosis, Fibroids, Polyps

iv. Malignant lesions of the genital tract Endometrial, Cervical, Vaginal

b. Systemic Diseases - Coagulation disorders, Endocrinological abnormalities and liver disorders.

Financial or Other, Competing Interest: None.

Submission 13-01-2017, Peer Review 07-02-2017,

Acceptance 13-02-2017, Published 06-03-2017.

Corresponding Author:

Dr. Seena K. B,

Assistant Professor,

Department of Obstetrics and Gynaecology,

Government Medical College, Thrissur.

E-mail:devu666@yahoo.co.in

DOI: $10.14260 /$ jemds $/ 2017 / 327$

\section{(c) $(1) \ominus$}

Dysfunctional uterine bleeding is one of the most frequently encountered problems in gynaecological practice.

It makes up about $10 \%$ cases in the Outpatient Clinic in the United States. It occurs most frequently at the extremes of menstrual life, but it can develop at any intervening time. ${ }^{2}$

Dysfunctional uterine bleeding is best defined as abnormal bleeding from the uterus in absence of organic disease of the genital tract, pregnancy or general bleeding disorder. ${ }^{3}$ The term applies to any abnormal uterine bleeding including disturbances of the menstrual cycle, regular and irregular uterine bleeding and alterations in the amount or duration of menstrual loss. But it most commonly implies excessive regular menstrual bleeding or essential menorrhagia (Van Eijkeren et al, 1989). Diagnosis is one of exclusion.

It is generally accepted that a detailed history, careful general and pelvic examination, cervical smear, uterine curettage, hysteroscopy or at least an endometrial biopsy are essential to exclude organic disease. There will nevertheless be a small proportion in whom some organic pathology is missed. Thus, DUB should always be regarded as a provisional diagnosis unless some endocrine or other dysfunction has been clearly demonstrated.

\section{MATERIALS AND METHODS}

The study is of prospective (Observational) type. All patients of adolescent age group, reproductive and perimenopausal age group with history suggestive of DUB registered as in patient and outpatient during the period August 1, 2010 to July 31, 2011 were studied. A total of 143 cases were selected. 
All cases where a pervaginal examination failed to reveal any recognisable pelvic pathology were included. All cases were subjected to cervical smear, ultrasound scan and selected after excluding organic pathology. Uterine size up to 6 weeks, small ovarian cysts and prolapsed uterus cases were not contraindications. Cases with obvious lesions of the cervix were excluded. Post-menopausal bleeding cases were also excluded.

The clinical detail of each patient was collected based on a preset proforma. Routine blood and urine examination and complete haemogram to rule out bleeding diathesis in the pubertal age group were carried out.

All selected cases were subjected to uterine curettage, $40 \%$ of the cases done during premenstrual and rest in bleeding phase. Curettings were sent for histopathological examination and reports were tabulated.

Appropriate treatment was advised to each case. Statistical analysis was done using the chi square test for goodness of fit and Z-test for proportion.

\section{RESULTS}

156 cases with a clinical diagnosis of dysfunctional uterine bleeding were selected after subjecting them to ultrasound scan; 3 cases were due to IUCD use, 10 cases were excluded as they were found to have other pathologies after curettage. Finally, 143 cases were taken. Of these there were 5 cases of puberty menorrhagia, 10 cases with severe anaemia for whom hormonal treatment was given without subjecting them to curettage and 5 cases where there were no endometrial curettings.

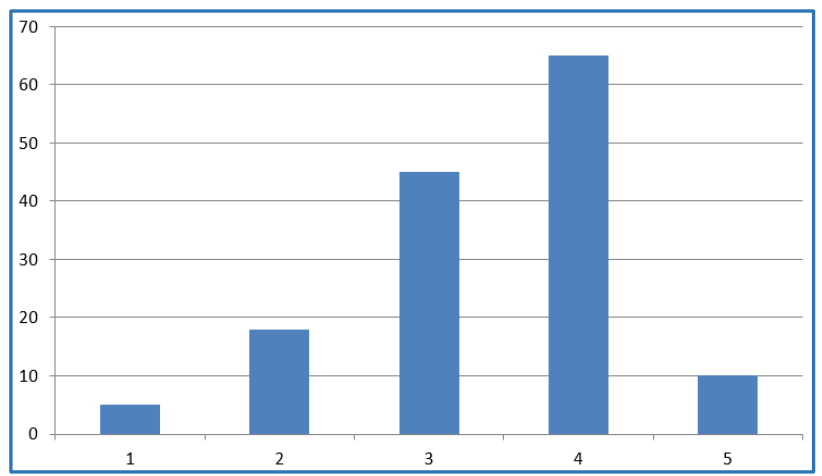

Figure 1. Age Pattern in the Study Group

1 ---- </- 20 years, 2 ----- 21 - 30 years, 3 ------ 31 - 40 years, 4 ---- 41 - 50 years, 5 ----- >/- 51 years.

\section{Age Pattern in the Study Group}

The graph shows that the older age groups (41 - 50 yrs.) are commonly affected, 65 cases (45.5\%). Ages ranged from 12 yrs. to 53 yrs. Cases of puberty menorrhagia constitute about $3.5 \%$ of the study group, 5 cases.

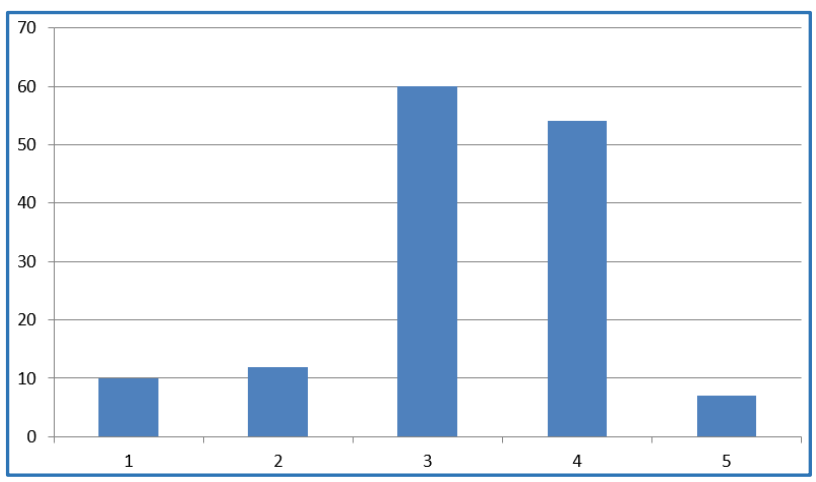

Figure 2. Relation to Parity - Para 1-1, Para 2-2, Para 3-3, Para 4-4, Para 5-5

\section{Parity and DUB}

Parity ranged from nullipara to para. There were 10 nulliparous cases. Multiparous mostly para 2 were commonly affected 60 cases, $41.96 \%$.

Menorrhagia was the most common complaint in 84 cases (58.74\%) followed by polymenorrhoea 20 cases $(13.99 \%)$ and metrorrhagia 17 cases $(13.33 \%)$. Applying the chi-square test for goodness of fit, the observed distribution is statistically significant $(\mathrm{x} 2=227.8, \mathrm{p}<0.001)$.

\section{Pattern of Bleeding in each Age Group} Menorrhagia

\begin{tabular}{|c|c|c|}
\hline Age Group & Number & Percentage \\
\hline$\leq 20$ Years & 4 & $4.76 \%$ \\
\hline $21-30$ Years & 10 & $11.9 \%$ \\
\hline $31-40$ Years & 23 & $27.38 \%$ \\
\hline $41-50$ Years & 40 & $47.6 \%$ \\
\hline$>51$ Years & 7 & $8.33 \%$ \\
\hline \multicolumn{2}{|c|}{ Table 1. Pattern of Bleeding in each Age Group } \\
\hline
\end{tabular}

Out of the total cases of menorrhagia, maximum (47.6\%) was in the age group 41 - 50 years followed by the age group $31-40$ years $(27.38 \%)$.

$\mathrm{X}^{2}=70.51, \mathrm{P}<.001$

which is highly significant.

Out of the total cases of metrorrhagia, maximum number of cases was in the $31-40$ age group. $\mathrm{X}^{2}=6.8 \mathrm{P}<.001$. Bleeding following period of amenorrhea was maximum in the 41 - 50 age group (71.43\%) $\mathrm{X}^{2}=12.29, \mathrm{p}<0.015$, which is significant. There were 2 cases of polymenorrhagia and oligomenorrhoea, both in the 41 - 50 age group. Out of the 20 cases of polymenorrhoea, maximum incidence was in the age group $31-40$ years, $\mathrm{X}^{2}=50.25 \%, \mathrm{p}<.001$, which is significant. Maximum incidence of hypermenorrhoea was in $41-50$ years, $X^{2}=9.5, p<.05$. There were 10 nullipara including 5 cases of puberty menorrhagia. Majority of the cases occurred in cases of last child birth $>/=5$ years, which is natural as the age group, most commonly affected is $41-50$ years. 


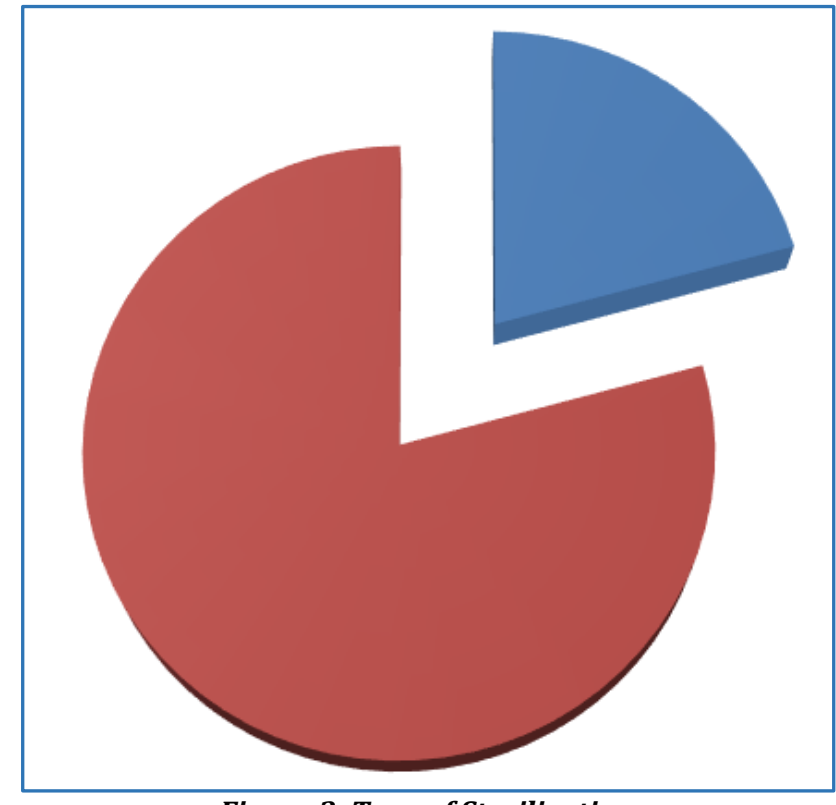

Figure 3. Type of Sterilisation

There were 80 cases that underwent puerperal sterilisation and 21 cases that underwent interval sterilisation.

Relation with IUCD

Menorrhagia 3

Total $=3$

In a total of 3 cases, the abnormal bleeding was due to insertion of copper containing IUCDs. On removal of the device, the bleeding pattern was normalised. All 3 of the cases with bleeding due to IUCD presented with menorrhagia and had $\mathrm{Hb}$ in the range $8-10 ; 2$ of the cases belonged to the age group 21 - 30 years and 1 in the 31 - 40 years' age group.

\section{Anaemia in DUB}

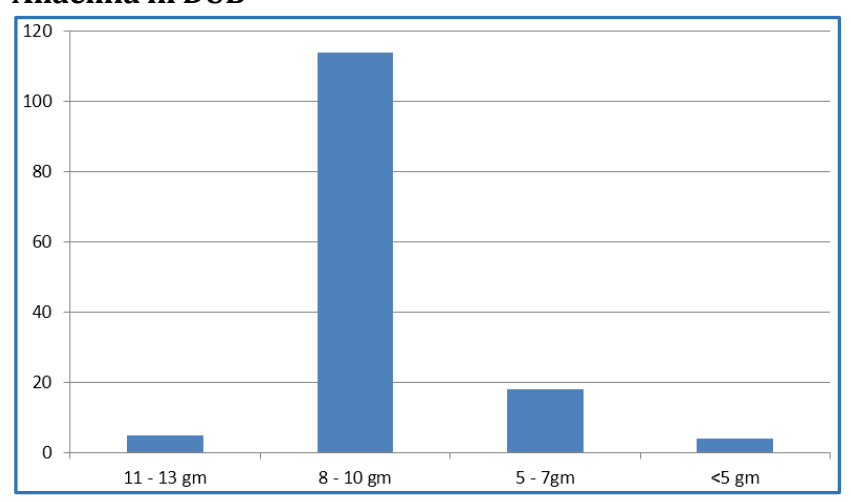

Figure 4. Degree of Anaemia-1-Hb 11 - 13 gm,

2-Hb 8 - $10 \mathrm{gm}, 3-\mathrm{Hb} 5$ - $7 \mathrm{gm}, 4-\mathrm{Hb}<5 \mathrm{gm}$
Majority of the cases, 114 had $\mathrm{Hb}$ in the range $8-10$ gm\%; Severe degree of anaemia $\mathrm{Hb}<5 \mathrm{gm} \%$ was found in $2.8 \%$; 4 cases of puberty menorrhagia had $\mathrm{Hb} 8-10 \mathrm{gm} \%$ and 1 in the group 5 - 7 gm\%.

\begin{tabular}{|c|c|c|}
\hline $\begin{array}{c}\text { Histopathology } \\
\text { of Endometrium }\end{array}$ & Number & $\mathbf{\%}$ \\
\hline Secretory & 36 & 29.27 \\
Disordered Proliferative & 21 & 17.07 \\
Lytic & 1 & 0.81 \\
Proliferative & 48 & 39.02 \\
Complex Hyperplasia & 5 & 4.06 \\
Simple Hyperplasia & 5 & 4.06 \\
Irregular Ripening & 1 & 0.81 \\
Atypical Hyperplasia Endometritis & 6 & 4.87 \\
& 0 & 0 \\
\hline Table 2. Histology of Endometrium in DUB Cases \\
\hline
\end{tabular}
Total $=123$

Proliferative endometrium formed the maximum number of cases (48) (39.02\%) followed by secretory endometrium (36) $(29.27 \%)$.

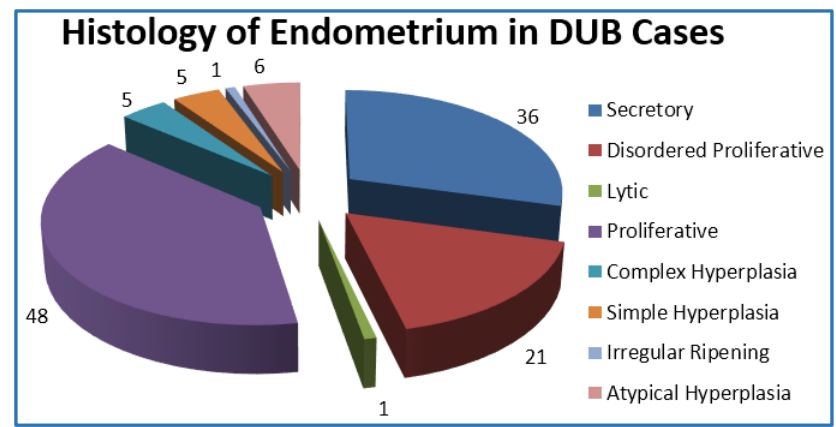

Figure 5. Histology of Endometrium in DUB Cases

\begin{tabular}{|c|c|c|c|c|c|}
\hline Type & \multicolumn{2}{|c|}{$<$ 40 Years } & \multicolumn{2}{|c|}{$>$ 40 Years } & Z - Value \\
\hline Proliferative Em. Secretory Em & 18 & 32.14 & 30 & 44.78 & $1.44(\mathrm{P}>.05)$ \\
Disordered Prolif Em & 29 & 51.79 & 7 & 10.45 & $5.04(\mathrm{P} .05)$ \\
Lytic Em. & 6 & 10.71 & 15 & 22.39 & $1.45(\mathrm{P}>.05)$ \\
Simple Hyperplasia & - & - & 1 & 1.49 & \\
Complex Hyperplasia & 3 & 5.36 & 2 & 2.99 & \\
Irregular Ripening & - & - & 5 & 7.46 & \\
Atypical Hyperplasia & - & - & 1 & 1.49 & \\
Endometritis & - & - & 6 & 8.96 & \\
Total & 56 & - & 67 & & \\
\hline Table 3. Distribution of Endometrial Lesions in various Age Groups, & \\
\hline
\end{tabular}


The chi square statistics was found to be highly significant. This indicates differential distribution of endometrial lesions in the two age groups. Proliferative, disordered proliferative and hyperplastic endometrium were more in the above 40 age group, whereas secretory endometrium was more common in the below 40 years' age group. The $\mathrm{Z}$ test for proportion was applied and the above observation of secretory endometrium in below 40 was found significant.

\begin{tabular}{|c|c|}
\hline Age Group & Number \\
\hline$<40$ Years & 47 \\
\hline$>40$ Years & 37 \\
\hline Total & 84 \\
\hline \multicolumn{2}{|c|}{ Table 4. Distribution of Normal Endometrium } \\
\hline
\end{tabular}

Normal endometrium was found in 47 cases in below 40 group and 37 cases in the above 40 group.

\begin{tabular}{|c|c|c|c|c|}
\hline \multicolumn{5}{|c|}{$\begin{array}{l}\text { Relation between } \\
\text { (Hyperplastic) and Age }\end{array}$} \\
\hline \multirow[t]{2}{*}{ Type } & \multicolumn{2}{|c|}{$>40$ Years } & \multicolumn{2}{|c|}{$<40$ Years } \\
\hline & Number & $\%$ & Number & $\%$ \\
\hline Disordered Prolif Em & 15 & 53.5 & 6 & 66.6 \\
\hline Simple Hyperplasia & 2 & 71.4 & 3 & 33.33 \\
\hline Complex Hyperplasia & 5 & 17.8 & & \\
\hline Atypical Hyperplasia & 6 & 21.43 & & \\
\hline Total & 28 & & 9 & \\
\hline
\end{tabular}

Hyperplastic endometrium was most common in the above 40 age group.

\begin{tabular}{|c|c|c|c|c|}
\hline Type & \multicolumn{2}{|c|}{$>$ 40 Years } & \multicolumn{2}{c|}{$<$ 40 Years } \\
\hline & Number & \% & Number & $\%$ \\
\hline Ovulatory & 29 & 51.79 & 8 & 121.12 \\
\hline Anovulatory & 27 & 48.21 & 58 & 87.88 \\
\hline \multicolumn{2}{|c|}{ Table 6. Distribution of Ovulatory and } \\
Anovulatory Bleeding Age Group \\
\hline
\end{tabular}

Anovulatory bleeding was more common in above 40 age group. $\mathrm{X} 2=42.38, \mathrm{P}<0.001$ highly significant.

\section{Medical Diseases Associated With DUB}

There were 8 cases of diabetes and 7 cases of hypertension in the study group.

Total $=143$

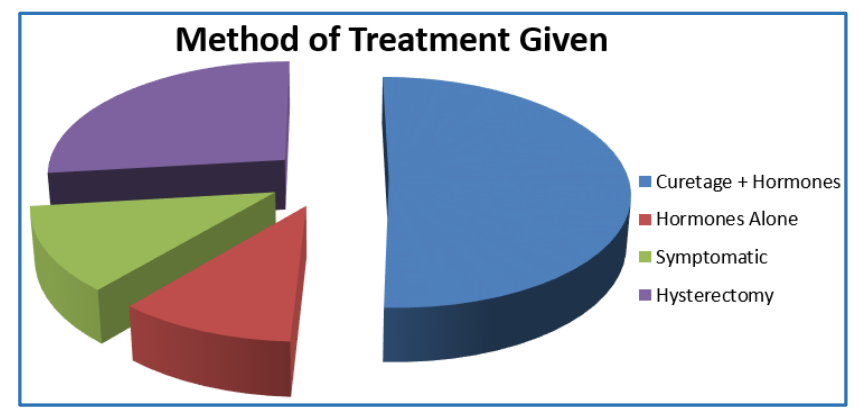

Figure 6. Treatment Given
Curettage along with NSAIDS to control the bleeding was given in 76 cases. Curettage with hormonal treatment (Combination OCPs or progesterone) was given for 34 cases; 10 cases presenting with heavy bleeding were treated with hormones, blood transfusion and haematinics. Symptomatic treatment was given for 5 cases of puberty menorrhagia with blood transfusion, haematinics and NSAIDS.

\section{Hysterectomy in DUB}

Hysterectomy, 3 as total and 15 as total abdominal with bilateral salpingo-oophorectomy were done. The cases included 6 cases of atypical hyperplasia and 12 cases who had recurrence of symptoms in spite of hormonal treatment and opted for hysterectomy.

\section{DISCUSSION}

Dysfunctional uterine bleeding is a common gynaecological problem. Careful study of the endometrium is necessary, especially in the older age group for in a few precursors of endometrial carcinoma will be found. Uterine curettage is useful since treatment can be planned depending on the histology and several unnecessary hysterectomies can be avoided. 8,9

\section{CONCLUSION}

Dysfunctional uterine bleeding was commonly seen in the age group 41 - 50 yrs. in our study. Menorrhagia was the most common bleeding complaint. Majority cases had $\mathrm{Hb}$ in the range 8 - $10 \mathrm{gm} \%$. In the above 40 age group, proliferative endometrium was common. And in below 40 age group secretory endometrium. Anovulatory bleeding was most common in the above 40 age group. Uterine curettage is useful for planning treatment and unnecessary hysterectomies can be avoided.

\section{REFERENCES}

[1] Wathen PI, Henderson MC, Witz CA. Abnormal uterine bleeding. Med clin NA 1995;79(2):329-44.

[2] Falcone T, Desjardins C, Bourque J, et al. Dysfunctional uterine bleeding in adolescents. J reprod med 1994;39(10):761-4.

[3] Queenan JT. Article on DUB. e-medicine 2005:1-17.

[4] Dallenbach-Hellweg. Histopathology of endometrium. 4th edn. Berlin Springer-Verlag 1987:p 136.

[5] Nedos S. DUB-Relation of endometrial histology to outcome. Am JO \& G 1971;109:103-7.

[6] Ferenczy, Bergeson. Classification of endometrial hyperplasia. Chap 13, Fox text book of gynaec pathology 1992:p 432.

[7] Kurman RJ, Kaminski PF, Norris HJ. The behavior of endometrial hyperplasia. A long-term study of untreated hyperplasia in 170 patients. Cancer 1985;56(2):403-12.

[8] McBRIDE JM. Pre-menopausal cystic hyperplasia and endometrial carcinoma. J O\&G Brit Emp 1959;66(2): 288-96.

[9] Ghosh, Sengupta KP. A study of the endometrium and cytohormonal pattern in DUB. J O\&G India 1968;18:311. 